\title{
Optimization of wear and hardness of Al-Zn-Mg-Cu alloy fabricated from recycled beverage can using response surface methodology
}

\author{
Abubakar Kazeem ${ }^{1,2}$ D $\cdot$ Nur Azam Badarulzaman² $\cdot$ Wan Fahmin Faiz Wan Ali $^{3}$
}

Received: 18 February 2020 / Accepted: 28 April 2020 / Published online: 13 June 2020

(c) Springer Nature Switzerland AG 2020

\begin{abstract}
A novel X7475 (Al-Zn-Mg-Cu) alloy was fabricated from recycled beverage cans (RBCs). Al was recovered from RBC. Zn and $\mathrm{Mn}$ were sourced from spent batteries, while Cu was sourced from copper wire. The weight percent (wt\%) Zn was varied at 4, 4.5 and 5 . Following the fabrication of rods, samples were taken through precipitation and artificial ageing at $475^{\circ} \mathrm{C}$ and $145^{\circ} \mathrm{C}$ respectively. The pin-on disc method within ASTM G99-17 was used for the wear test, while hardness post-mortem was done using ASTM E18 specifications. Wear mass loss (WML) and hardness were optimized using response surface methodology (RSM). The least WML of $0.017 \mathrm{~g}$ and maximum hardness of $142 \mathrm{HV}$ were obtained from an alloy fabricated using $5 \mathrm{wt} \% \mathrm{Zn}$, when subjected to a load (L) of $30 \mathrm{~N}$, speed (S) of $400 \mathrm{RPM}$ and time (T) of $10 \mathrm{~min}$. The MWL of $0.011 \mathrm{~g}$ and least hardness of $71 \mathrm{HV}$ were observed in an alloy of $4 \mathrm{wt} \% \mathrm{Zn}$ under a load of $20 \mathrm{~N}$, with S, and T at $150 \mathrm{RPM}$ and $6 \mathrm{~min}$ apiece. Formation of hardening precipitates like $\mathrm{Al}_{2} \mathrm{CuMg}, \mathrm{MgZn}_{2}$ and $\mathrm{CuAl}_{2}$, were suggested to be responsible for the low WML and hardness observed in the alloys. The result confirmed the significant of the optimization model at a confident interval of $95 \%\left(R^{2}=0.9531\right)$. Additional experiment was suggested for correlating hardness with tensile strength.
\end{abstract}

Keywords Response-surface-methodology (RSM) $\cdot$ STI policy $\cdot$ Recycled-beverage-can $\cdot$ X7475 $\cdot$ Wear

\section{Introduction}

The attractive properties of aluminium and alloys have placed the alloy at strategic and advantageous position, making it suitable for both industrial and experimental applications as captured in Tuleun et al. [1]. The possibilities of recycling the beverage can as a secondary source of aluminium has thrown open opportunities of using RBCs in engineering applications. Mechanical properties are improved by the addition of alloying elements and heat treatments $[2,3]$. For instance, the $7 x x x$ series find applications in aerospace, automobile, military and nuclear applications, when given suitable heat treatments. Key among other properties, which guide the materials engineer on the area of applications of a particular material, is the high strength to weight ratio and mechanical performance $[4,5]$. The $7 x x x$ alloys are admirable on both properties [6].

Previous studies on 7xxx alloys concentrated more on sourcing alloy from commercially available means [6-8]. The study conducted by [9] was not conducted using RBCs and [10] only reinforced the $7 x x x$ alloy with $\mathrm{Al}_{2} \mathrm{O}_{3}$. On the

Electronic supplementary material The online version of this article (https://doi.org/10.1007/s42452-020-2836-7) contains supplementary material, which is available to authorized users.

$\triangle$ Nur Azam Badarulzaman, azam@uthm.edu.my | ${ }^{1}$ Department of Science Policy and Innovation Studies, National Centre for Technology Management (NACETEM), North Central, PMB 715, Abuja, Nigeria. ${ }^{2}$ Faculty of Mechanical and Manufacturing Engineering, Universiti Tun Hussein Onn Malaysia (UTHM), 86400 Parit Raja, Johor, Malaysia. ${ }^{3}$ Faculty of Mechanical Engineering, Universiti Teknologi Malaysia (UTM), 81310 Skudai, Johor, Malaysia. 
other hand, $\mathrm{RBC}$ s are returned as cans, making it one of the most recycled aluminium globally. Australia has a beverage can recycle rate of $80 \%$, Japan has $78.5 \%$, while USA recycles $63 \%$ of aluminium cans [11]. Attempts made at converting RBCs to 7xxx alloys are rare in the literature [2].

Wear occurs when loss of material is progressive from the surface of a solid. This is made possible through mechanical interface between a stationary body against a moving solid. Abrasive wear follows when a solid object is loaded against elements of a material with identical or greater hardness [12]. For clarifications on the pin-on-disc method used in investigating the wear mass loss (WML), the experimental alloy herein reported is the stationary body (pin), while the moving solid is the disc part of the test machine used in conducting the experiment.

The optimization of mechanical properties such as MWL and hardness of the X7475 are also scanty in the literature. This alloy finds application in the aerospace and automobile industry, such as fabrication of electric vehicle frames and bumper beam applications, hence information on mechanical properties are key in simulating the crash worthiness on ANSYS software. Interestingly, the Nigeria Science Technology and Innovation (STI) policy visibly promotes the adoption of new and innovative materials for her emerging automobile industry [13], hence the need for studies of this nature.

On the above premise, the aim of this paper was to optimize the mechanical properties (MWL and hardness) of the novel X7475 (Al-Zn-Mg-Cu) experimental alloy fabricated from RBCs. The forgoing served as an introduction to this paper. Subsequently, materials and design of experiment, results and analysis of optimized properties and conclusions drawn from the findings are presented in Sects. 2, 3 and 4 respectively.

\section{Materials and method}

A new $\mathrm{X7475}$ (Al-4-5Zn-Mg-Cu) alloy samples were fabricated using the stir casting method. The raw materials were drawn from recycled sources. More than $3 \mathrm{~kg}$ of RBCs were collected from recycle centres in Parit Raja, Batu Pahat, Malaysia. Beverage cans were compacted and converted to ingots using the gas fired-high capacity furnace. Other constituents such as $\mathrm{Zn}$ and $\mathrm{Mn}$ were sourced from spent Hawk batteries of the GB/T 8897.2-2008 specifications. Recycled Cu-wire was obtained from standing fan coil, while Mg was as supplied.

Samples of experimental alloys were fabricated using graphite crucible in a portable JT0332 model induction furnace. In order to prepare the crucible for casting and eradicate moisture, the crucible was preheat at $200^{\circ} \mathrm{C}$. Casting commenced by introducing $\mathrm{Al}-\mathrm{chip}$, then $\mathrm{Zn}$, an amalgam of $70 \% \mathrm{Cu}-30 \% \mathrm{Al}, \mathrm{Mn}$ and $\mathrm{Mg}$ were introduced in that order. The melting was done at $1100^{\circ} \mathrm{C}$, while stirring was achieved utilizing TAC 1803-Pentec hand mixer to attain homogenization of the alloy. Pouring into improvised steel permanent mould was done at $720 \pm 10^{\circ} \mathrm{C}$. Castings and experimental parameter variations followed the layout presented in Table 1.

After the casting, samples were left to age at room temperature for $24 \mathrm{~h}$. Samples were then solution treated at $475^{\circ} \mathrm{C}$, quenched in clean water and artificially aged at $145^{\circ} \mathrm{C}$ for 540 min using Carbolite HTF 1800 furnace. The heat treatment process was done in accordance with AMS 2771 specifications. Coupons for Vickers hardness were prepared using ASTM E92-17, while the test was conducted following ASTM E18 specifications respectively. Microhardness study was done using Shimadzu HMV-2, C227-E013 automatic tester. Load, indenting time and probed points were $490.3 \mathrm{mN}(0.05 \mathrm{HV}), 10 \mathrm{~s}$ and 9 points respectively. WML investigation followed ASTM G99-17, using the Kemet/Metkon FORCIPOL 2 V pin-ondisk apparatus. During the investigation, sliding distance was maintained at $50 \mathrm{~mm}$ throughout. The experimental mix between Load $(\mathrm{L})$, speed $(\mathrm{S})$ and time $(\mathrm{T})$ were determined using the Design of Experiment (DOE). The WML (g) was obtained by taking the difference between the initial and final weights of each sample. Weight was measured using the enclosed Mettler Toledo balancing apparatus. Morphology investigations and elemental analysis (EDX) of worn surfaces were done on Hitachi VP-SEM, SU1510 machine. Table 1 shows the experimental parameters.

\subsection{Design of experiment (DOE)}

Design Expert v10 was embraced in obtaining the parameters used in optimizing the WML and hardness properties. The Response Surface Methodology (RSM) and Central Composite techniques were used as study and design types respectively. The quadratic design approach with a total of 16 runs and 0 Blocks was employed using randomized experimental subtype. The 16 runs shall be identified as samples 1-16, herein labelled as S1-S16. The parameters used as input for the DOE is presented in Table 2.

Table 1 Layout of experimental parameters used in the DOE for wear mass loss showing the variation in the wt $\% \mathrm{Zn}$, loads (N), time (min) and speed (RPM)

\begin{tabular}{llll}
\hline wt\%Zn & Load (N) & Time (min.) & Speed (RPM) \\
\hline 4 & 20 & 6 & 150 \\
4.5 & 30 & 10 & 270 \\
5 & 40 & 15 & 400 \\
\hline
\end{tabular}


Worthy of note is that Table 1 shows the input parameters used in generating the expected output presented in Table 2. During the design of experiment, the codes used in representing each factor, the maximum and minimum values were the inputs. On the other hand, the Design Expert software coded each factor and assigned values based on the input parameters. These parameters were used by the software in generating the mean and standard deviation (SD) for each factor presented in Table 2. The mean and standard deviation are useful in assessing the variation between the maximum and minimum values for each factor considered during the experiment. These data were further used by the DOE in developing the optimization model and the interactions between all the factors understudied herein.

Analysis of variance (ANOVA) was employed in assessing the interactions between the experimental factors as presented in Table 3. This was required to gain better understanding of the interactions between and within the experimental parameters for optimization.

\section{Results and discussion}

\subsection{Wear mass loss and hardness}

A WML of $0.019 \mathrm{~g}$ was recorded against S1, with hardness of $104 \mathrm{HV}$. This sample was fabricated using $\mathrm{Al}-4.5 \mathrm{Zn}-1.5 \mathrm{Mg}-1 \mathrm{Mn}-0.35 \mathrm{Cu}$, then subjected to a direct load (L) of $40 \mathrm{~N}$ for $10 \mathrm{~min}$. The speed of the pin against the disc was at 270 RPM. The result in Table 4 equally shows that an increase in the wt\% of $\mathrm{Zn}$ from 4.5 to $5.0 \mathrm{wt} \%$, resulted in decrease in the WML from 0.019 to $0.013 \mathrm{~g}$ in S2. Whereas there was an increase in the hardness from 104 to $139 \mathrm{HV}$. The result suggest that the increase in hardness was due to the change in grain size of the alloy due
Table 2 DOE input parameters adopted and output on experimental scheme, the mean and standard deviation (SD)

\begin{tabular}{lllrrlllc}
\hline Factor & Name & Units & Min. & Max. & Coded & Values & Mean & SD \\
\hline A & wt $\%$ Zn & wt\% & 4 & 5 & $-1.0=4$ & $1.000=5$ & 4.5 & 0.40824 \\
B & Load & Newton & 20 & 40 & $-1.0=20$ & $1.000=40$ & 30 & 8.16497 \\
C & Speed & RPM & 150 & 400 & $-1.0=150$ & $1.000=400$ & 265 & 96.3328 \\
D & Time & Minutes & 6 & 15 & $-1.0=6$ & $1.000=15$ & 9.1875 & 3.42965 \\
\hline
\end{tabular}

Table 3 Analysis of variance for response surface 2FI model

\begin{tabular}{llllllllllll}
\hline Response & Name & Units & Obs & Analysis & Min & Max & Mean & SD & Ratio & Trans & Model \\
\hline R1 & WML & $\mathrm{g}$ & 16 & Polynomial & 0.011 & 0.045 & 0.0256 & 0.0106199 & 4.09091 & Inverse & $2 \mathrm{FI}$ \\
R2 & Hardness & HV & 16 & Polynomial & 71.8555 & 140.454 & 109.598 & 24.4632 & 1.95467 & Inverse & $2 \mathrm{FI}$ \\
\hline
\end{tabular}

Table 4 DOE and experimental responses (WML and hardness) obtained following the implementation of the design

\begin{tabular}{lllllll}
\hline Sample no. & Zn (wt\%) & $\mathrm{L}(\mathrm{N})$ & $\mathrm{S}(\mathrm{RPM})$ & $\mathrm{T}(\mathrm{M})$ & WML $(\mathrm{g})$ & Hardness (HV) \\
\hline S1 & 4.5 & 40 & 270 & 10 & 0.019 & 104 \\
S2 & 5 & 20 & 150 & 15 & 0.013 & 139 \\
S3 & 5 & 30 & 400 & 10 & 0.017 & 142 \\
S4 & 4 & 30 & 270 & 10 & 0.023 & 75 \\
S5 & 4 & 20 & 150 & 6 & 0.011 & 71 \\
S6 & 4 & 40 & 150 & 6 & 0.031 & 72 \\
S7 & 5 & 20 & 400 & 15 & 0.045 & 100 \\
S8 & 4.5 & 20 & 270 & 10 & 0.036 & 76 \\
S9 & 5 & 40 & 150 & 6 & 0.045 & 120 \\
S10 & 4.5 & 30 & 270 & 15 & 0.027 & 100 \\
S11 & 4 & 40 & 400 & 6 & 0.039 & 123 \\
S12 & 4.5 & 30 & 270 & 6 & 0.021 & 114 \\
S13 & 5 & 40 & 150 & 6 & 0.020 & 129 \\
S14 & 4 & 20 & 400 & 6 & 0.023 & 134 \\
S15 & 4.5 & 30 & 270 & 10 & 0.021 & 121 \\
S16 & 5 & 30 & 270 & 10 & 0.019 & 129 \\
\hline
\end{tabular}


to the increase in $\mathrm{Zn}$, while the heat treatment supported the precipitates in aluminium [2].

For clarifications, the effect of increase in the wt $\% \mathrm{Zn}$ of the experimental $\mathrm{Al}-\mathrm{Zn}-\mathrm{Mg}$ alloy and heat treatment was reported in previous studies. It was clear that the amount of total solute elements in the $\mathrm{Al}-\mathrm{Zn}-\mathrm{Mg}-\mathrm{Cu}$ alloys has a direct effect on the age hardening process of the alloy by improving the precipitation mechanism. The reason partly is that the formation of correct stoichiometric ratio of solute elements for $M g Z n_{2}$ and $M_{3} Z_{3} \mathrm{Al}_{2}$ phases are composition dependent. This is important because improved hardness is a function of the correct $\mathrm{Mg} / \mathrm{Zn}$ ratio of 1:5 (for the formation of the $\mathrm{MgZn}_{2}$-phase). Therefore, the $5 \mathrm{wt} \%$ in $\mathrm{S} 2$ in combination with the artificial aged at $145^{\circ} \mathrm{C}$ for 540 min strongly effect on the supersaturation degree of solid solution formed within the Al-matrix to improve the hardness and reduce the mass wear loss of the alloy [14].

Accordingly, at a load of $20 \mathrm{~N}$ and 150 RPM were applied on S5, an alloy with $4 \mathrm{wt} \% \mathrm{Zn}$. The experiment lasted for $6 \mathrm{~min}$ and resulted in the least wear and hardness of $0.011 \mathrm{~g}$ and $71 \mathrm{HV}$ respectively. The correlation between both properties suggest the role of the wt $\mathrm{Zn}$ and artificial ageing in the mechanical properties of the novel $\mathrm{Al}-\mathrm{Zn}-\mathrm{Mg}-\mathrm{Cu}$ alloy. The implication was that the alloy with least $Z n$ content had less hardening precipitates while the formation of second phases like $\mathrm{MgZn}_{2}$ was suggested to be affected by the $\mathrm{Zn}$ wt\% [15]. However, the MWL test only lasted for $6 \mathrm{~min}$, hence the effect was minimal on the worn surface as against the case of S2 which lasted for $15 \mathrm{~min}$ and had a MWL of $0.017 \mathrm{~g}$. It should therefore be noted that alloys with higher wt $\% \mathrm{Zn}$ withstood more wear load for a longer time like was observed in S2, S3 and S7.

The obtainable maximum WML of $0.045 \mathrm{~g}$ was observed in S7, an alloy of 5 wt\% Zn, when loaded with $20 \mathrm{~N}$ at a speed of $400 \mathrm{RPM}$ for $15 \mathrm{~min}$. The same alloy had a hardness of $100 \mathrm{HV}$. The observed WML was due to the high speed used in the test. However, the $20 \mathrm{~N}$ load produced a low frictional force due to the low pressure placed on the surface of the sample, but the rate of material removal was high. The uneven removal of soft asperities supported the separation of wear debris on the sliding track. The effect of high speed and increase in load on the sample forced the alloy to impact more on the disc. These factors reflected on the friction and increase in WML as shown in S11 [16]. This result is similar to the one observed in S9, with the same load of $40 \mathrm{~N}$. The surface morphology is akin to the one presented in Fig. 3b, c and is consistent with previous studies [17].

\subsection{ANOVA for mass wear loss}

The ANOVA presented in Table 5 revealed that with an F-value of 5.29, the model generated was sufficient in predicting the wear of our novel $\mathrm{Al}-\mathrm{Zn}-\mathrm{Mg}-\mathrm{Cu}$ alloys. The implication is that the parameters measured were responsible for the result obtained, and not due to noise. There was only a $3.99 \%$ chance that the model presented and responses were merely due to perturbations [18]. Consequently, the overall model is significant, whereas the lack of fit was highly insignificant. When the lack of fit is insignificant, it is an indication that the model fitted well with the experimental result earlier presented in Table 4.

The significance of the model was evidenced in the values of "Prob $>F$ " that was less than 0.0500 . Here, the speed of the pin $(C), A B, A C, B D, C D$ were significant model terms. With the values of the aforementioned parameters above 0.1000 , it means that the model terms fully reflected the mechanical properties of this experimental alloy.

The 0.05 Lack of Fit was insignificant relative to the model terms. This is an indication that the model was
Table 5 ANOVA for wear mass loss

\begin{tabular}{lccccll}
\hline Source & Sum of squares & df & Mean quare & F value & $p$ Value Prob $>F$ & Significant \\
\hline Model & 4938.01 & 10 & 493.80 & 5.29 & 0.0399 & \\
A-Zn\% & 484.38 & 1 & 484.38 & 5.19 & 0.0717 & \\
B-L & 183.88 & 1 & 183.88 & 1.97 & 0.2193 & \\
C-S & 967.08 & 1 & 967.08 & 10.37 & 0.0235 & \\
D-T & 398.32 & 1 & 398.32 & 4.27 & 0.0937 & \\
AB & 1055.90 & 1 & 1055.90 & 11.32 & 0.0200 & \\
AC & 997.41 & 1 & 997.41 & 10.69 & 0.0222 & \\
AD & 8.60 & 1 & 8.60 & 0.092 & 0.7737 & Not significant \\
BC & 431.14 & 1 & 431.14 & 4.62 & 0.0843 & \\
BD & 853.93 & 1 & 853.93 & 9.15 & 0.0292 & \\
CD & 989.69 & 1 & 989.69 & 10.61 & 0.0225 & \\
Residual & 466.50 & 5 & 93.30 & & & \\
Lack of fit & 80.69 & 4 & 20.17 & 0.052 & 0.9881 & \\
Pure error & 385.80 & 1 & 385.80 & & &
\end{tabular}


significant. Table 6 shows $\mathrm{R}^{2}=0.9137$ and adjusted $\mathrm{R}^{2}=0.7411$ which are very close to the fitted model.

Further, Table 7 present the result of SD and $2 \mathrm{FI}$ model factors respectively. The 8.507 adequate precision strengthened the capability of the model, in terms of level of accuracy.

This was supported by the leverage value of 1.0000 which measured the signal to noise $(\mathrm{S} / \mathrm{N})$ ratio. The result outdid the required $\mathrm{S} / \mathrm{N}$ ratio of 4 as desirable. This means that the signal was higher and the model was sufficient in describing the relationship between MWL and parameters affecting this property in particular. The relationship between the parameters clearly shown on Table 7 were the actual factors measured as presented in Eq. (1). The equation may be used in predicting the MWL of this experimental alloy.

Final equation for WML, in terms of actual factors is as presented:

\subsection{ANOVA for hardness}

The ANOVA for hardness presented in Table 8 captured all the parameters effecting on the hardness of the experimental alloys.

The model was significant at $p$ value of 0.0098 that means it was sufficient in describing the effect of speed (S), Zn wt\%, time ( $\mathrm{T}$ ) and the interaction between these parameters on the hardness of the $\mathrm{Al}-\mathrm{Zn}-\mathrm{Mg}-\mathrm{Cu}$ alloys.

Additionally, F-value of 10.15 further established the significance of the model. With "Prob $>F^{\prime \prime}<0.0500$, the model terms were significant. In this case $\mathrm{Zn}$ wt $\%$ and the speed of wear test were substantial to the model obtained. Assuming the Prob values were ' 0.1000 , then the model terms would not have been significant.

When Lack of Fit was not significant relative to the pure error, then it means the model captured the main parameters, but not noise. By extension, there are $28.40 \%$

$$
\begin{aligned}
\frac{1}{W M L}= & 8.629 \times 10^{3}-2.51659 \times 10^{3} * Z n \%-164.8 * L-13.60 * S+268.35 * T \\
& +47.909 * Z n \% * L+3.98 * Z n \% * S+1.261 * Z n \% * 8.25 \times 10^{-3} * L * S \\
& -5.17 * L * T-0.445 * S * T
\end{aligned}
$$

Table 6 Standard deviation and R-square for wear mass loss

\begin{tabular}{llll}
\hline Std. dev. & 9.66 & R-squared & 0.9137 \\
Mean & 45.70 & Adj R-squared & 0.7411 \\
C.V. \% & 21.13 & Pred R-squared & N/A \\
PRESS & N/A & Adeq precision & 8.507 \\
-2 log likelihood & 99.37 & BIC & 129.87 \\
& & AICc & 187.37 \\
\hline
\end{tabular}

chance that this "Lack of Fit F-value" could be due to irrelevant interferences. The meaning was that any parameter that was not captured by the model developed using the experiential result herein presented is not relevant to the hardness of the alloys. The justification for measuring the lack of fit was to ensure that the model fit and represent the property well. The SD for hardness and $R^{2}$ were $9.32 \times 10^{-4}$ and 0.9531 respectively as shown in Table 9. The meaning of the low SD was that the differences in the measures of central tendencies of the result (hardness) obtained are very low. On the other hand, the 0.9531 regression means that the relationship between
Table 7 2FI model factors for wear mass loss

\begin{tabular}{lcccrrr}
\hline Factor & Coefficient estimate & df & Standard error & $\begin{array}{l}95 \% \mathrm{Cl} \\
\text { Low }\end{array}$ & $\begin{array}{l}\text { 95\% Cl } \\
\text { High }\end{array}$ & \multicolumn{1}{l}{ VIF } \\
\hline Intercept & & 1 & 3.63 & 33.89 & 52.54 & \\
A-Zn \% & 14.26 & 1 & 6.26 & -1.83 & 30.36 & 4.20 \\
B-L & -12.44 & 1 & 8.86 & -35.22 & 10.34 & 8.42 \\
C-S & -15.08 & 1 & 4.68 & -27.12 & -3.04 & 2.10 \\
D-T & -16.10 & 1 & 7.79 & -36.14 & 3.93 & 5.67 \\
AB & 239.55 & 1 & 71.21 & 56.51 & 422.59 & 434.76 \\
AC & 248.77 & 1 & 76.09 & 53.19 & 444.36 & 481.07 \\
AD & 2.84 & 1 & 9.35 & -21.20 & 26.88 & 6.58 \\
BC & 10.32 & 1 & 4.80 & -2.02 & 22.65 & 1.91 \\
BD & -232.72 & 1 & 76.92 & -430.46 & -34.98 & 445.53 \\
CD & -250.49 & 1 & 76.91 & -448.19 & -52.79 & 493.70 \\
\hline
\end{tabular}


Table 8 ANOVA for hardness

\begin{tabular}{llrlrll}
\hline Source & Sum of squares & \multicolumn{1}{c}{ df } & Mean square & Value & $p$ Value Prob $>\mathrm{F}$ & \\
\hline Model & $8.823 \mathrm{E}-005$ & 10 & $8.823 \mathrm{E}-006$ & 10.15 & 0.0098 & Significant \\
A-Zn \% & $2.735 \mathrm{E}-005$ & 1 & $2.735 \mathrm{E}-005$ & 31.48 & 0.0025 & \\
B-L & $4.069 \mathrm{E}-006$ & 1 & $4.069 \mathrm{E}-006$ & 4.68 & 0.0828 & \\
C-S & $7.361 \mathrm{E}-006$ & 1 & $7.361 \mathrm{E}-006$ & 8.47 & 0.0334 & \\
D-T & $1.428 \mathrm{E}-006$ & 1 & $1.428 \mathrm{E}-006$ & 1.64 & 0.2561 & \\
AB & $2.204 \mathrm{E}-006$ & 1 & $2.204 \mathrm{E}-006$ & 2.54 & 0.1721 & \\
AC & $1.638 \mathrm{E}-006$ & 1 & $1.638 \mathrm{E}-006$ & 1.89 & 0.2281 & \\
AD & $1.952 \mathrm{E}-006$ & 1 & $1.952 \mathrm{E}-006$ & 2.25 & 0.1942 & \\
BC & $1.425 \mathrm{E}-007$ & 1 & $1.425 \mathrm{E}-007$ & 0.16 & 0.7022 & Not significant \\
BD & $1.264 \mathrm{E}-006$ & 1 & $1.264 \mathrm{E}-006$ & 1.45 & 0.2818 & \\
CD & $2.202 \mathrm{E}-006$ & 1 & $2.202 \mathrm{E}-006$ & 2.53 & 0.1723 & \\
Residual & $4.344 \mathrm{E}-006$ & 5 & $8.689 \mathrm{E}-007$ & & & \\
Lack of fit & $4.185 \mathrm{E}-006$ & 4 & $1.046 \mathrm{E}-006$ & 6.56 & 0.2840 & \\
Pure error & $1.596 \mathrm{E}-007$ & 1 & $1.596 \mathrm{E}-007$ & & & \\
Cor total & $9.257 \mathrm{E}-005$ & 15 & & & & \\
\hline
\end{tabular}

Table 9 Standard deviation and R-square for hardness

\begin{tabular}{llll}
\hline Std. dev. & $9.321 \mathrm{E}-004$ & R-squared & 0.9531 \\
Mean & $9.637 \mathrm{E}-003$ & Adj R-squared & 0.8592 \\
C.V. \% & 9.67 & Pred R-squared & N/A \\
PRESS & N/A & Adeq precision & 9.088 \\
-2 log likelihood & -196.50 & BIC & -166.00 \\
\hline
\end{tabular}

the parameters measured and the hardness were well represented at $95.31 \%$. This further strengthened the capability of the models developed in adequately predicting the property.

The "Adequacy Precision" measures the signal to noise ratio $(\mathrm{S} / \mathrm{N})$. From the result presented in Table 9, the desirable was to have a ratio greater than 4 . The $S / N$ ratio of 9.088 obtained indicated that the model developed was accurate, precise and sufficient in describing the effect of $w t \% \mathrm{Zn}$, load (L), time ( $\mathrm{T}$ ) and speed (S) on the hardness of this alloy. The complete model was generated from Table 10 using the $2 \mathrm{FI}$ model factors for hardness.

Final equation for hardness, in terms of actual factors:

$$
\begin{aligned}
\frac{1}{\text { Hardness }}= & -0.35251+0.10956 * \mathrm{Zn} \%+7.53 \times 10^{-3} * \mathrm{~L}+4.90 \times 10^{-4} *-8.82 \times 10^{-3} \\
& * \mathrm{~T}-2.188 \times 10^{-3} * \mathrm{Zn} \% * \mathrm{~L}-1.613 \times 10^{-4} * \mathrm{Zn} \% * \mathrm{~S}-6.011 \times 10^{-4} \\
& * \mathrm{Zn} \% * \mathrm{~T}+1.50 \times 10^{-7} * \mathrm{~L} * \mathrm{~S}+1.98 \times 10^{-4} * \mathrm{~L} * \mathrm{~T}+1.50 \times 10^{-7} \\
& * \mathrm{~L} * \mathrm{~S}+1.98 \times 10^{-4} * \mathrm{~L}^{*} \mathrm{~T}+2.10 \times 10^{-5} * \mathrm{~S} * \mathrm{~T}
\end{aligned}
$$

Table 102 FI model factors for hardness

\begin{tabular}{lccclrr}
\hline Factor & Coefficient estimate & df & Standard error & $\begin{array}{l}95 \% \mathrm{Cl} \\
\text { Low }\end{array}$ & \multicolumn{1}{l}{$\begin{array}{l}95 \% \mathrm{Cl} \\
\text { High }\end{array}$} & \multicolumn{1}{l}{ VIF } \\
\hline Intercept & $9.741 \mathrm{E}-003$ & 1 & $3.501 \mathrm{E}-004$ & $8.841 \mathrm{E}-003$ & 0.011 & \\
A-Zn $\%$ & $-3.390 \mathrm{E}-003$ & 1 & $6.042 \mathrm{E}-004$ & $-4.943 \mathrm{E}-003$ & $-1.837 \mathrm{E}-003$ & 4.20 \\
B-L & $-1.851 \mathrm{E}-003$ & 1 & $8.551 \mathrm{E}-004$ & $-4.049 \mathrm{E}-003$ & $3.476 \mathrm{E}-004$ & 8.42 \\
C-S & $-1.316 \mathrm{E}-003$ & 1 & $4.521 \mathrm{E}-004$ & $-2.478 \mathrm{E}-003$ & $-1.537 \mathrm{E}-004$ & 2.10 \\
D-T & $9.643 \mathrm{E}-004$ & 1 & $7.522 \mathrm{E}-004$ & $-9.692 \mathrm{E}-004$ & $2.898 \mathrm{E}-003$ & 5.67 \\
AB & -0.011 & 1 & $6.872 \mathrm{E}-003$ & -0.029 & $6.720 \mathrm{E}-003$ & 434.76 \\
AC & -0.010 & 1 & $7.342 \mathrm{E}-003$ & -0.029 & $8.793 \mathrm{E}-003$ & 481.07 \\
AD & $-1.353 \mathrm{E}-003$ & 1 & $9.025 \mathrm{E}-004$ & $-3.673 \mathrm{E}-003$ & $9.672 \mathrm{E}-004$ & 6.58 \\
BC & $1.876 \mathrm{E}-004$ & 1 & $4.632 \mathrm{E}-004$ & $-1.003 \mathrm{E}-003$ & $1.378 \mathrm{E}-003$ & 1.91 \\
BD & $8.953 \mathrm{E}-003$ & 1 & $7.423 \mathrm{E}-003$ & -0.010 & 0.028 & 445.53 \\
CD & 0.012 & 1 & $7.422 \mathrm{E}-003$ & $-7.264 \mathrm{E}-003$ & 0.031 & 493.70 \\
\hline
\end{tabular}



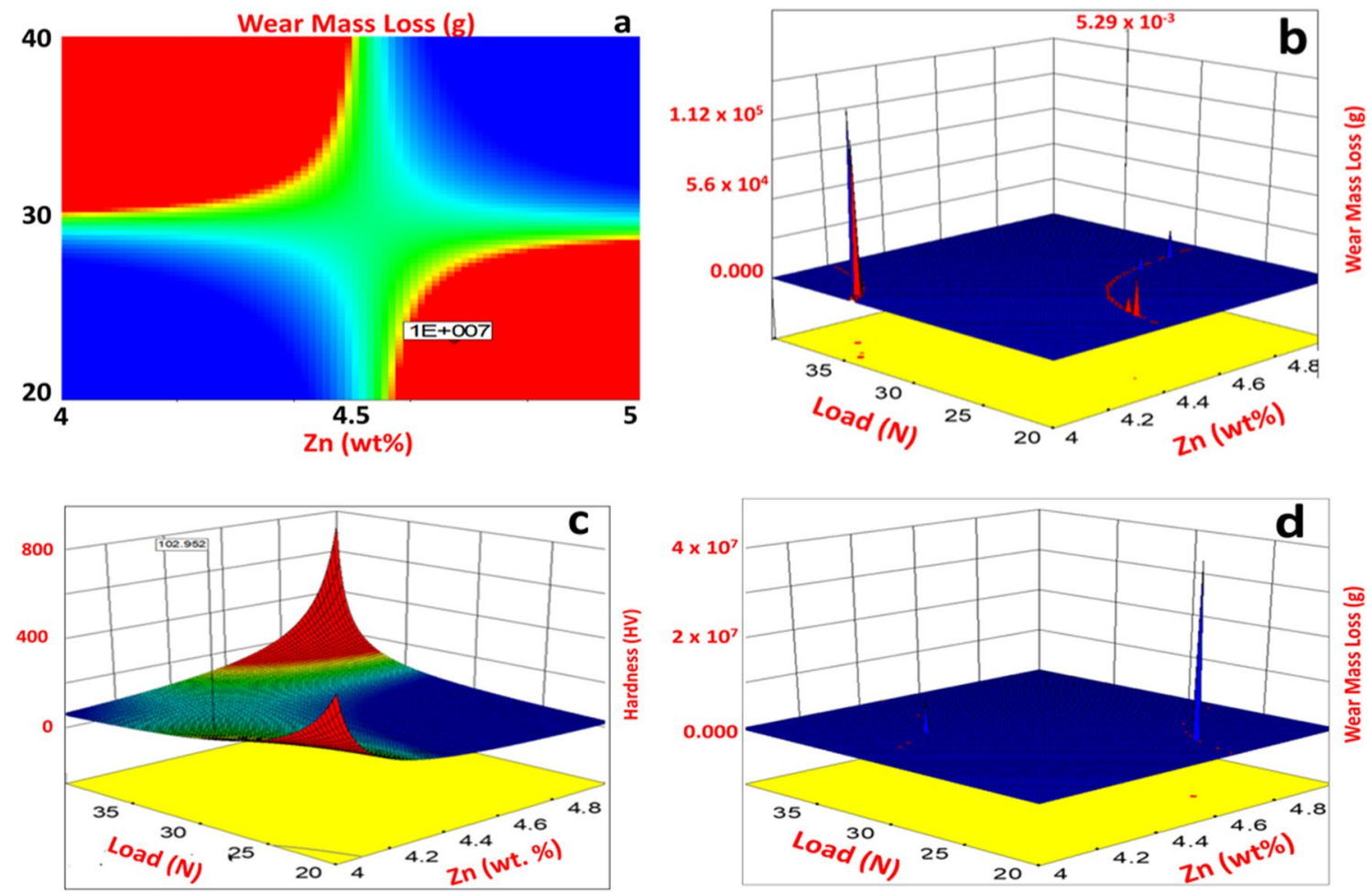

Fig. 1 Contour plot for hardness (a) response surface plot for wear mass loss (b) response surface plot for hardness (c) and (d) for WML

The graphs in Fig. 1a represent contour plot indicating the effect of $w t \% Z n$, load and time take on the hardness of the X7475 experimental alloys. The interaction between all aforementioned parameters on the WML was captured in the response surface plot shown in Fig. $1 \mathrm{~b}$.

The contour plot inferred that an increase in $w t \% \mathrm{Zn}$ was beneficial to hardness and WML. This was because increase in $\mathrm{Zn}$ resulted in increase in the formation of hardening precipitates $\left(\mathrm{MgZn}_{2}\right)$ which were dissolved in the a-Al after heat treatment. The report of Kumar and Sreebalaji [19] confirmed that increase in precipitates in the form of reinforcement particles increased the amount of stick out particles that reduced MWL. The continuous removal of the particles accounted for decrease in the MWL. The relationship represented in Fig. 1c portrays an inverse relationship exist between the load applied during the wear test and the hardness of the alloy. On the other hand, Fig. $1 \mathrm{~d}$ showed that an increase in load increased the MWL.

\section{Optimization of MWL and hardness}

The main aim of the optimization was to minimize MWL and maximize hardness using the experimental parameters. Figure $2 \mathrm{a}$ followed the-smaller-the-better principle of optimality [20]. The desirability was 1 . The implication was that the least obtainable wear loss was considered as optimal, since the less the wear of the alloy, the better the load bearing capacity and the abrasive resistance. On hardness (Fig. 2b), the higher-the-better-optimization criteria was adopted. This is because the goal was to obtain the maximum load bearing capacity from the $X 7475$ experimental alloy for engineering applications. From the parameter point of view (Fig. 2c), the Zn composition, load, speed and time must be set at $5 \mathrm{wt} \%, 33 \mathrm{~N}, 347 \mathrm{RPM}$, and 13 min respectively as optimality conditions, in order to obtain the optimum WML of $0.107 \mathrm{~g}$ and hardness of 421 HV. The justification for correlating MWL with hardness was to reduce the effect of perturbations on both properties. The ramps solution tool was used as the optimization approach to detect the most influential parameters on the alloys.

\section{Morphological investigation of worn surfaces}

There are two most important stages in the adhesive wear mechanism. The first stage was described as the scuffing phase which was characterized by the breaking 


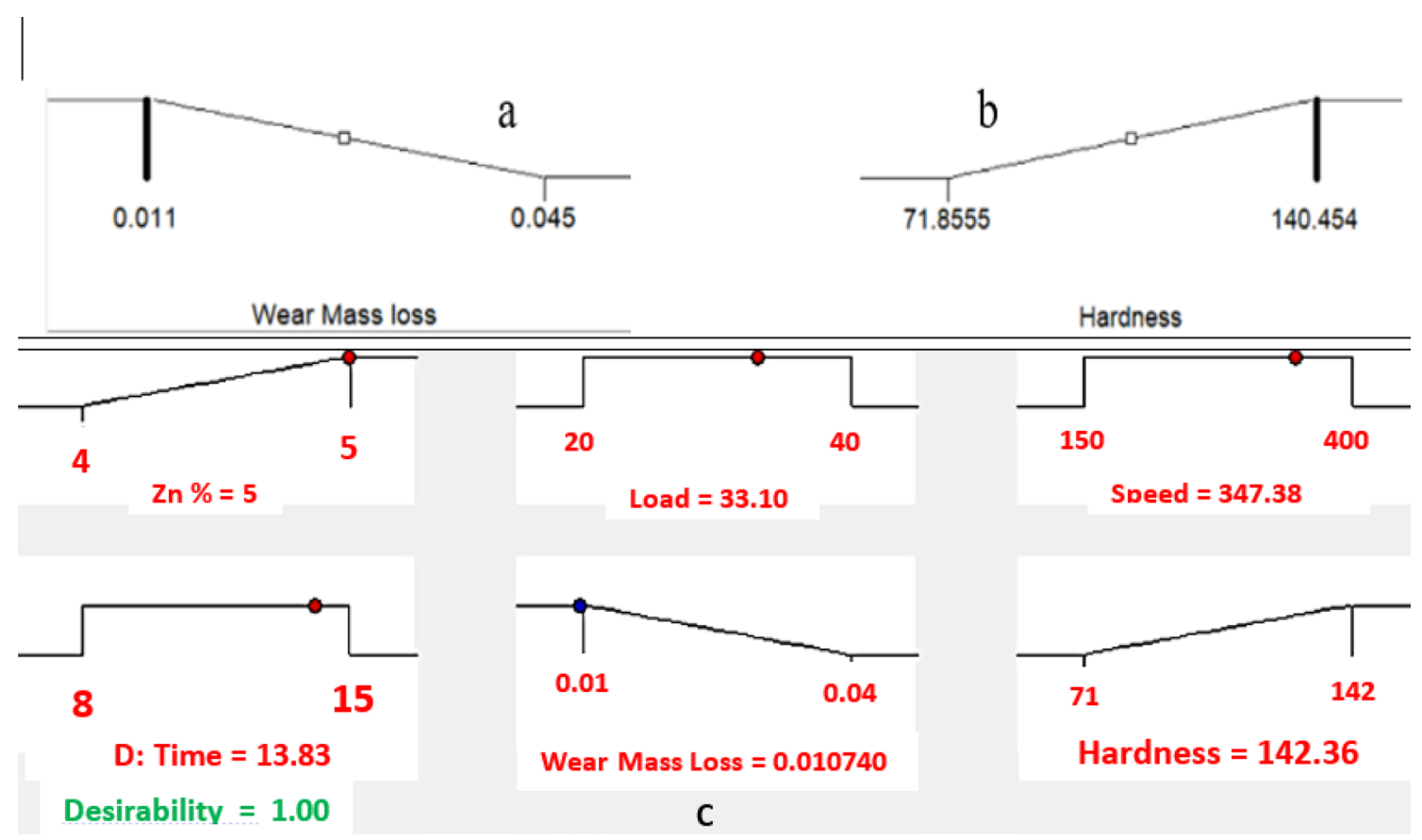

Fig. 2 Optimization solution ramps for wear mass loss (a), hardness (b) and parameters used in optimizing both properties (c)

of tribo-film. The second is referred to galling; involving mechanical rubbing [21]. The description on Fig. 3b shows the direction of the sliding velocity which correspond to the first phase and demonstrates a wear site. The higher wear rate on the site was due to the initial and sudden impact of the load on the material surface [22]. The wear resistance was improved as a result of the heat treatment [22].

The continuous rotation of the sample on the disc with the load of $20 \mathrm{~N}$ enforced a metal pool out (Fig. 3a) in $\mathrm{S6}$ with $4 \mathrm{wt} \% \mathrm{Zn}$. The pool out of the material was as a result of the ploughing initiated (Fig. 3b), corresponding to the galling phase of the wear mechanism earlier explained. Cracks owing to fatigue on the surface resulted in the removal of particles on the surface; wear debris (Fig. 3c) [23].

Although, the precipitated particles such as $\mathrm{Al}_{2} \mathrm{CuMg}_{4}$ and $M g Z n_{2}$ were suggested to be formed [24] due to heat treatments, based on the typical EDX analysis of the grain boundaries as shown in the microstructure (Fig. 4). From microstructural point of view, these hardening phases posed resistance to the cracks, but the opposing asperities and sustained sliding distance in the face of loads in form of pressure forced the wear shown in Fig. $3 \mathrm{c}$ to occur.
This study supported the observations of Sudagar et al. [22] who reported that heat treatment and $\mathrm{Zn}$ content were the reasons for the high wear resistance posed by 7075-T6 aluminium alloys. The area of the contact surfaces increased after sliding a few distance within the test time of $1 \mathrm{~min}$ when the load was $20 \mathrm{~N}$ as shown in Fig. 3a. The abrupt increase in initial value was due to the sudden contact on the surface of the sample and the counter surface. This was in addition to load and adhesion force. This explained the reason for initial high wear loss as characterized in all the samples.

The EDX analysis suggest the formation of $\mathrm{Al}_{2} \mathrm{CuMg}$, $M g Z n_{2}$ and $\mathrm{CuAl}_{2}$, which were responsible for the low WML observed in the alloys.

\section{Conclusion}

Design parameters to obtain optimum mechanical properties (mass wear loss and hardness) of a novel experimental X7475 alloy fabricated from RBCs were obtained using the $\mathrm{RSM}$. The following conclusions were drawn based on the findings of this study; 

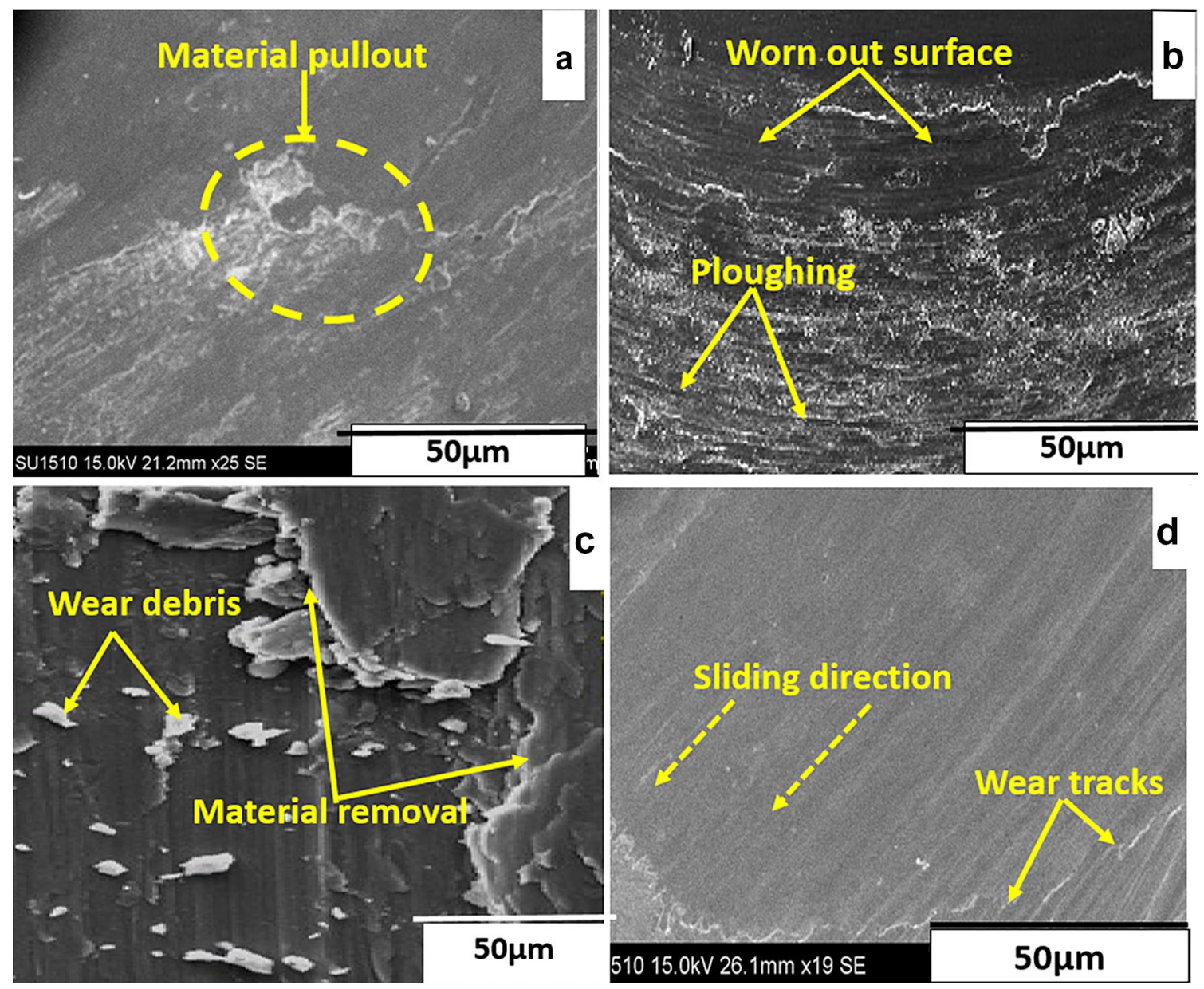

Fig. 3 Typical morphology of worn surface of the $X 7475$ alloys showing a metal pool from the wear site of S6 (Al-4Zn-1.5Mg$1 \mathrm{Mn}-0.35 \mathrm{Cu}$ ) with load at $20 \mathrm{~N}$, Speed at $150 \mathrm{RPM}$ and test time at $6 \mathrm{~min}$, $\mathbf{b}$ ploughing due to frictional force of the disc on pin involv-

ing S7 (Al-5Zn-1.5Mg-1Mn-0.35Cu) with load at $20 \mathrm{~N}$, Speed at 400 RPM, and test time at $15 \mathrm{~min}, \mathrm{c}$ wear debris observed in S5 and d wear track along sliding direction observed in S7. All micrographs were taken at $50 \times \mu \mathrm{m}$ magnification

1. The maximum hardness and minimum WML of $142 \mathrm{HV}$ and $0.017 \mathrm{~g}$ were observed in an alloy fabricated using Al- $5 \mathrm{Zn}-1.5 \mathrm{Mg}-1 \mathrm{Mn}-0.35 \mathrm{Cu}$, when subjected to a load of $30 \mathrm{~N}$, speed of $400 \mathrm{RPM}$ and time of $10 \mathrm{~min}$. On the other hand, the WML of $0.011 \mathrm{~g}$ and least hardness of $71 \mathrm{HV}$ was observed in an alloy of $4 \mathrm{wt} \% \mathrm{Zn}$ under a load of $20 \mathrm{~N}$, with S, and T set at 150 RPM and 6 min apiece. This result suggest that the higher the wt $\% \mathrm{Zn}$ in the experimental alloy, the lower the WML, while reverse was the case with hardness.

2. With the desirability set at 1 , the parameter to obtain the optimum WML and hardness of $0.107 \mathrm{~g}$ and 421 $\mathrm{HV}$ were obtained as $5 \mathrm{wt} \%, 33 \mathrm{~N}, 347 \mathrm{RPM}$, and $13 \mathrm{~min}$

against Zn composition, load, speed and time respectively.

3. The microstructure analysis suggested the formation of the hardening precipitates, which was responsible for the improved mechanical properties observed in this alloy.

4. The result of ANOVA, through the optimization of the mechanical properties, confirmed the significance of the models developed for WML and hardness at a confident interval $(\mathrm{Cl})$ of $95 \%\left(\mathrm{R}^{2}=0.9531\right)$. However, additional experiment is required in correlating hardness with ultimate tensile strength as a means of validating the optimality test herein reported. 


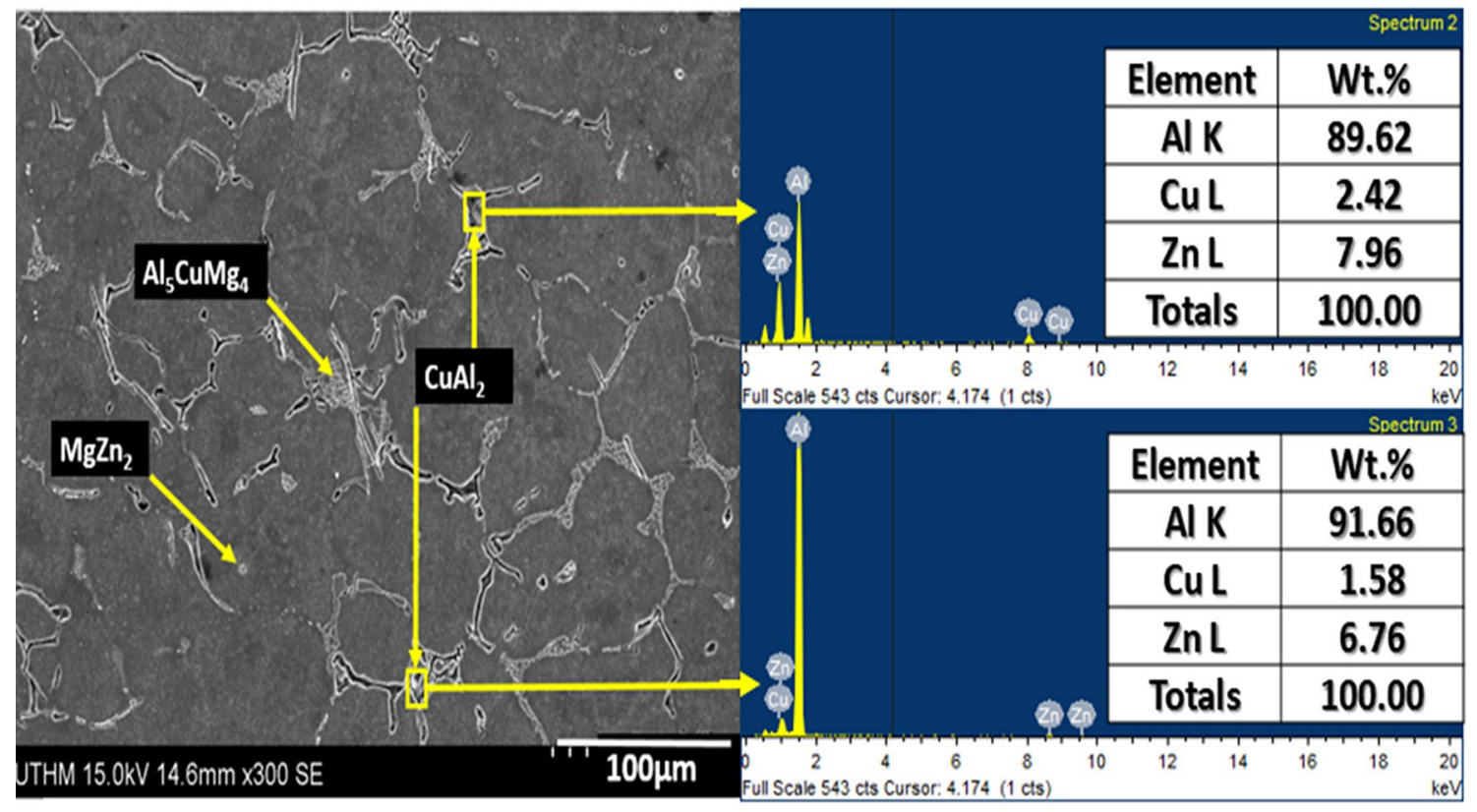

Fig. 4 Microstructure analysis of sample (S9) Al- $5 \mathrm{Zn}-1.5 \mathrm{Mg}-1 \mathrm{Mn}-0.35 \mathrm{Cu}$ alloy showing grain boundaries and EDX of elements with possible hardening precipitate formations along grains after solution treated at $475^{\circ} \mathrm{C}$, and artificial aged at $145^{\circ} \mathrm{C}$ for $540 \mathrm{~min}$

Authors' contribution KA: conceptualization, methodology, original draft preparation, NA: supervision, materials, WFF: supervision, reviewing and editing.

\section{Compliance with ethical standards}

Conflict of interest The authors declare that they have no conflict of interest.

\section{References}

1. Tuleun LT, Amine JD, Abubakar K (2014) Effect of variation in magnesium and copper on mechanical properties of X7475 aluminium alloy. Am J Mater Sci Eng 2(4):54-61

2. Kazeem A, Badarulzaman NA, Fahmin W, Bin F, Ali W (2019) Effect of isothermal heat treatment on hardness of X7475 aluminium alloys. J Adv Res Fluid Mech Therm Sci 55(2):233-239

3. Li B, Pan Q, Chen C, Wu H, Yin Z (2016) Effects of solution treatment on microstructural and mechanical properties of $\mathrm{Al}-\mathrm{Zn}-\mathrm{Mg}$ alloy by microalloying with Sc and Zr. J Alloys Compd 664:553-564

4. Pagliarello $A$ (2012) Effects of modified solution heat treatment on the mechanical properties and stress corrosion cracking susceptibility of aluminum alloy 7075

5. Liu Y, Jiang D, Xie W, Hu J, Ma B (2014) Solidification phases and their evolution during homogenization of a DC cast Al-8.35Zn2.5Mg-2.25Cu alloy. Mater Charact 93(2):173-183

6. Yang XB, Chen JH, Liu JZ, Qin F, Xie J, Wu CL (2014) A high-strength AIZnMg alloy hardened by the T-phase precipitates. J Alloys Compd 610:69-73

7. Alrubaie K, Barroso E, Godefroid L (2006) Fatigue crack growth analysis of pre-strained 7475-T7351 aluminum alloy. Int J Fatigue 28(8):934-942

\section{SN Applied Sciences}

A SPRINGER NATURE journal
8. Yin S et al (2017) Effects of $\mathrm{Zn} / \mathrm{Gd}$ ratio on the microstructures and mechanical properties of Mg-Zn-Gd-Zr alloys. Mater Sci Eng A 695(April):135-143

9. Tocci M, Pola A, Girelli L, Lollio F, Montesano L, Gelfi M (2019) Wear and cavitation erosion resistance of an AIMgSc alloy produced by DMLS. Metals (Basel) 9(3):308

10. Al-Salihi HA, Mahmood AA, Alalkawi HJ (2019) Mechanical and wear behavior of AA7075 aluminum matrix composites reinforced by $\mathrm{Al}_{2} \mathrm{O}_{3}$ nanoparticles. Nanocomposites 5(3):67-73

11. He M (2006) Analysis of the recycling method for aluminum soda cans. University of Southern Queensland, Toowoomba

12. Umale T, Mahajan Y, Peshwe DR (2013) Study of abrasive wear of Al-Zn-Mg alloy by Taguchi method. Int J Eng Res Technol 2:2937-2943

13. F.-M.-S.-T. (FMST) (2012) Nigeria science, technology and innovation (STI) policy. FMST, Abuja

14. Ghiaasiaan TR (2015) Controlled diffusion solidification process (CDS) of Al-7xxx wrought alloys. McMaster University, Hamilton

15. Wen K et al (2017) Aging behavior and fatigue crack propagation of high $\mathrm{Zn}$-containing $\mathrm{Al}-\mathrm{Zn}-\mathrm{Mg}-\mathrm{Cu}$ alloys with zinc variation. Prog Nat Sci Mater Int 27(2):217-227

16. Sol ID, Batista M, Salguero J, Vazquez-Martinez JM (2018) Application of pin-on-disc techniques for the study of tribological interferences in the dry machining of A92024-T3 (Al-Cu) alloys. Materials (Basel) 3(1235):1-11

17. Zhang Q, Gu J, Wei S, Qi M (2019) Differences in dry sliding wear behavior between $\mathrm{Al}-12 \mathrm{Si}-\mathrm{CuNiMg}$ alloy and its composite reinforced with $\mathrm{Al}_{2} \mathrm{O}_{3}$ fibers. Materials (Basel) 12(11):1-11

18. Manikandan C (2017) Experimental investigation on mechanical behavior's of stir cast aluminium 6061-SiC MMC using Taguchi technique. Int Res J Eng Technol 4(4):124-128

19. Kumar KR, Sreebalaji VS (2016) Desirability based multiobjective optimisation of abrasive wear and frictional behaviour of aluminium (Al/3.25Cu/8.5Si)/fly ash composites. Tribol Mater Surf Interfaces 9(3):128-136 
20. David JE, Smart DSR, Babu R, Gnanaprakash N (2017) Investigations on dry sliding wear behaviour of $\mathrm{LM} 13 / \mathrm{SiC} / \mathrm{Gr}$ hybrid composites by response surface methodology 3 . Response surface methodology (RSM) for prediction of wear rate. Int J Pure Appl Math 117(9):95-99

21. Wasim Akram M, Polycarpou AA (2015) Wear mechanisms of gray cast iron in the presence of environmentally friendly hydrofluoroolefin-based refrigerant and the effect of tribofilm formation. $J$ Tribol 137(4):041602

22. Sudagar J, Venkateswarlu K, Lian J (2009) Dry sliding wear properties of a 7075-T6 aluminum alloy coated with Ni-P $(\mathrm{h})$ in different pretreatment conditions. J Mater Eng Perform 19(7):810-818
23. Singh RC, Ranganath MS, Saxena AK (2015) Investigation of wear behavior of aluminium alloy and comparison with pure investigation of wear behavior of aluminium alloy and comparison with pure aluminium. In: International conference of advance research and innovation (ICARI-2015), March 2015, pp 305-314

24. Peng $X$ et al (2018) Precipitate behavior and mechanical properties of enhanced solution treated $\mathrm{Al}-\mathrm{Zn}-\mathrm{Mg}-\mathrm{Cu}$ alloy during nonisothermal ageing. J Alloys Compd 735:964-974

Publisher's Note Springer Nature remains neutral with regard to jurisdictional claims in published maps and institutional affiliations. 